\title{
A Rice Calcium- and Calmodulin-Dependent Protein Kinase Restores Nodulation to a Legume Mutant
}

\author{
Olivier Godfroy, Frédéric Debellé, Ton Timmers, and Charles Rosenberg \\ Laboratoire des Interactions Plantes-Microorganismes INRA-CNRS, BP52627, 31326 Castanet-Tolosan Cedex, France
}

Submitted 26 October 2005. Accepted 12 January 2006.

\begin{abstract}
The Medicago truncatula DMI3 gene encodes a calciumand calmodulin-dependent protein kinase (CCaMK) that is necessary for the establishment of both rhizobial and mycorrhizal symbioses. The two symbiotic signaling pathways diverge downstream of $\mathrm{DMI3}$; therefore, it has been proposed that legumes have evolved a particular form of CCaMK, acting like a switch able both to discriminate between rhizobial and mycorrhizal calcium signatures and to trigger the appropriate downstream signaling pathway. To test this hypothesis, we examined whether a CCaMK gene from a nonlegume species was able to restore the rhizobial symbiotic properties of a $M$. truncatula dmi3 mutant. Our results show that a CCaMK gene from rice can restore nodule formation, indicating that CCaMKs from nonlegumes can interpret the calcium signature elicited by rhizobial Nod factors and activate the appropriate downstream target. The nodules did not contain bacteria, which suggests that DMI3 is also involved in the control of the infection process.
\end{abstract}

Additional keywords: rhizobium, symbiosis.

Symbiotic associations between soil microorganisms and plant roots play a role of considerable ecological and economical importance. The arbuscular mycorrhizal (AM) symbiosis is a very ancient association (more than 400 million years old) between fungi of the phylum Glomeromycota and more than $80 \%$ of terrestrial plant species, which allows the translocation into roots of various nutrients such as phosphate (Harrison 2005). The association between soil bacteria, collectively called rhizobia, and legumes is more recent (approximately 60 million years old), and allows plant growth to be independent of an added nitrogen source. The bacterial partner induces the formation of specialized organs, called nodules, in which it reduces atmospheric nitrogen into ammonia. The establishment of the symbiotic rhizobium-legume interaction relies on the production by the bacterial partner of extracellular lipochito-oligosaccharidic signaling molecules, the so-called Nod factors (NFs) (Dénarié et al. 1996; Geurts and Bisseling 2002). These bacterial signals, which control nodule organogenesis and infection in a host-specific manner, elicit, at very low concentrations (nano- to picomolar), a number of responses in various tissues of host roots.

Genetic analysis in the model legumes Medicago truncatula and Lotus japonicus has led to the identification of a set of genes involved in NF perception and signal transduction (Oldroyd et al. 2005). Receptor-like kinase proteins containing

Corresponding author: C. Rosenberg; Telephone: +33 5612854 63; Fax: +33561285061; E-mail: crosen@toulouse.inra.fr
LysM domains are likely to be involved in the perception of NFs and the triggering of a signal transduction cascade leading to the induction of early symbiotic responses (Limpens et al. 2003; Madsen et al. 2003; Radutoiu et al. 2003). In M. truncatula, five genes controlling steps of this signaling cascade have been identified (Fig. 1A), including the three genes $D M I 1, D M I 2$, and $D M I 3$, which are necessary both for NF signal transduction and for the establishment of the AM symbiosis (Catoira et al. 2000), suggesting that genes involved in the ancient mycorrhizal signaling pathway have been recruited for the more recent rhizobium-legume Nod signaling pathway (Gianinazzi-Pearson 1996).

All $d m i$ mutants are blocked very early in both symbiotic interactions. However, dmil and dmi2 mutants do not show periodic $\mathrm{Ca}^{2+}$ oscillations $\left(\mathrm{Ca}^{2+}\right.$ spiking) in response to NFs, in contrast to dmi3 mutants (Wais et al. 2000). This suggests that $D M I 3$ could be involved in the recognition and interpretation of this calcium signal. Indeed, DMI3 has been shown to encode a calcium- and calmodulin-dependent protein kinase (CCaMK) (Lévy et al. 2004; Mitra et al. 2004), located in the nucleus (Smit et al. 2005). Thus, the role of DMI3 in the NF signaling pathway could be to sense $\mathrm{Ca}^{2+}$ oscillations induced by NFs and to transduce the signal by phosphorylating downstream target proteins, such as transcription factors (Lévy et al. 2004; Oldroyd and Downie 2004; Smit et al. 2005). Though very little is known about the mycorrhizal symbiotic signaling pathway, the structure of the DMI3 protein suggests that it also could be involved in sensing a calcium signal generated upon recognition of the fungus. Furthermore, the fact that CCaMKs are present in a unique copy in various nonlegume species able to form mycorrhizal associations, such as lily or rice (Patil et al. 1995; International Rice Sequencing Project 2005), but not in Arabidopsis thaliana, which is unable to establish this type of symbiosis, suggests that CCaMKs also could play a role in mycorrhizal signaling pathways in nonlegumes. During evolution, legumes could have evolved a particular form of these enzymes, such as DMI3 in the case of $M$. truncatula, which acquired the ability to sense $\mathrm{Ca}^{2+}$ spiking elicited by NFs.

Downstream of the signaling pathway controlled by the DMI genes, the mycorrhizal and rhizobial signaling pathways diverge and elicit events specific to each symbiosis. In $M$. truncatula, $D M I 3$ is the last known gene common to both symbioses; therefore, it is tempting to hypothesize that the DMI3 protein could act like a switch, selectively activating the downstream transduction pathway leading either to nodulation or to mycorrhization, according to the nature of the calcium signal perceived (Lévy et al. 2004) (Fig. 1A). This hypothesis implies that legumes evolved a form of CCaMK able both to discriminate between calcium signatures elicited by NFs and by mycorrhizal fungi, and to activate the target protein or proteins triggering the appropriate downstream transduction pathway. 
In this study, we tested this hypothesis by examining whether a CCaMK from a nonlegume species can restore the rhizobial symbiotic properties to a $M$. truncatula dmi3 mutant. We show that the putative orthologue of DMI3 from rice can restore nodulation ability to the mutant, indicating that a nonlegume CCaMK is able to recognize the NF-elicited calcium signature, and subsequently activate the downstream transduction pathway leading to nodulation.

Furthermore, we observed that, in the $d m i 3$ mutant carrying the rice $C C a M K$ gene, the rhizobial infection process is altered. This indicates that DMI3 controls both nodule organogenesis and infection, and that only the former function can be complemented efficiently by a nonlegume gene.

\section{RESULTS}

Identification of a putative $\mathrm{DMI} 3$ orthologue in rice.

Blast analysis of the complete rice genome sequence (International Rice Sequencing Project 2005) identified a single gene encoding a protein with the characteristic CCaMK structure, showing $69 \%$ identity and $83 \%$ similarity with $M$. truncatula DMI3 (Fig. 2). In particular, the kinase active site, the calmodulin binding domain, and the three EF-hands are highly conserved, suggesting that DMI3 and the rice CCaMK could have similar functional properties. A full-length cDNA from a flower library encoding the rice $\mathrm{CCaMK}$ was available at the
Rice Genome Resource Center. This cDNA was cloned into the pGreen0049 binary vector under the control of either the CaMV $35 S$ or the $M t D M I 3$ promoter.

These $\mathrm{p} 35 S$-riceCCaMK and $\mathrm{p} D M I 3$-riceCCaMK constructs then were introduced into $M$. truncatula dmi3-1 mutant plants carrying a pMtENOD11-GUS fusion. The MtENOD11 gene is used as a molecular marker of the early stages of the nodulation process and its expression is controlled by the NF signaling pathway (Catoira et al. 2000; Journet et al. 2001). The TRV25 mutant, which carries the dmi3-1 null allele, does not exhibit root hair curling, infection thread formation, cortical cell division, or nodule formation in the presence of the $M$. truncatula symbiont Sinorhizobium meliloti 2011 (Catoira et al. 2000). In addition, no hyphal penetration within dmi3-1 roots is detected in the presence of AM fungi, although appressorium formation is observed (Catoira et al. 2000; Weidmann et al. 2004). Because the nodulation phenotype of the dmi3-1 mutant is root controlled (Lévy et al. 2004), we used Agrobacterium rhizogenes-mediated transformation to generate plants with transgenic roots carrying the constructs to be tested for their ability to restore symbiotic properties.

\section{The rice CCaMK restores Nod factor induction} of MtENOD11.

To start studying the ability of the rice $\mathrm{CCaMK}$ to restore the NF signaling pathway, we determined whether the pres-
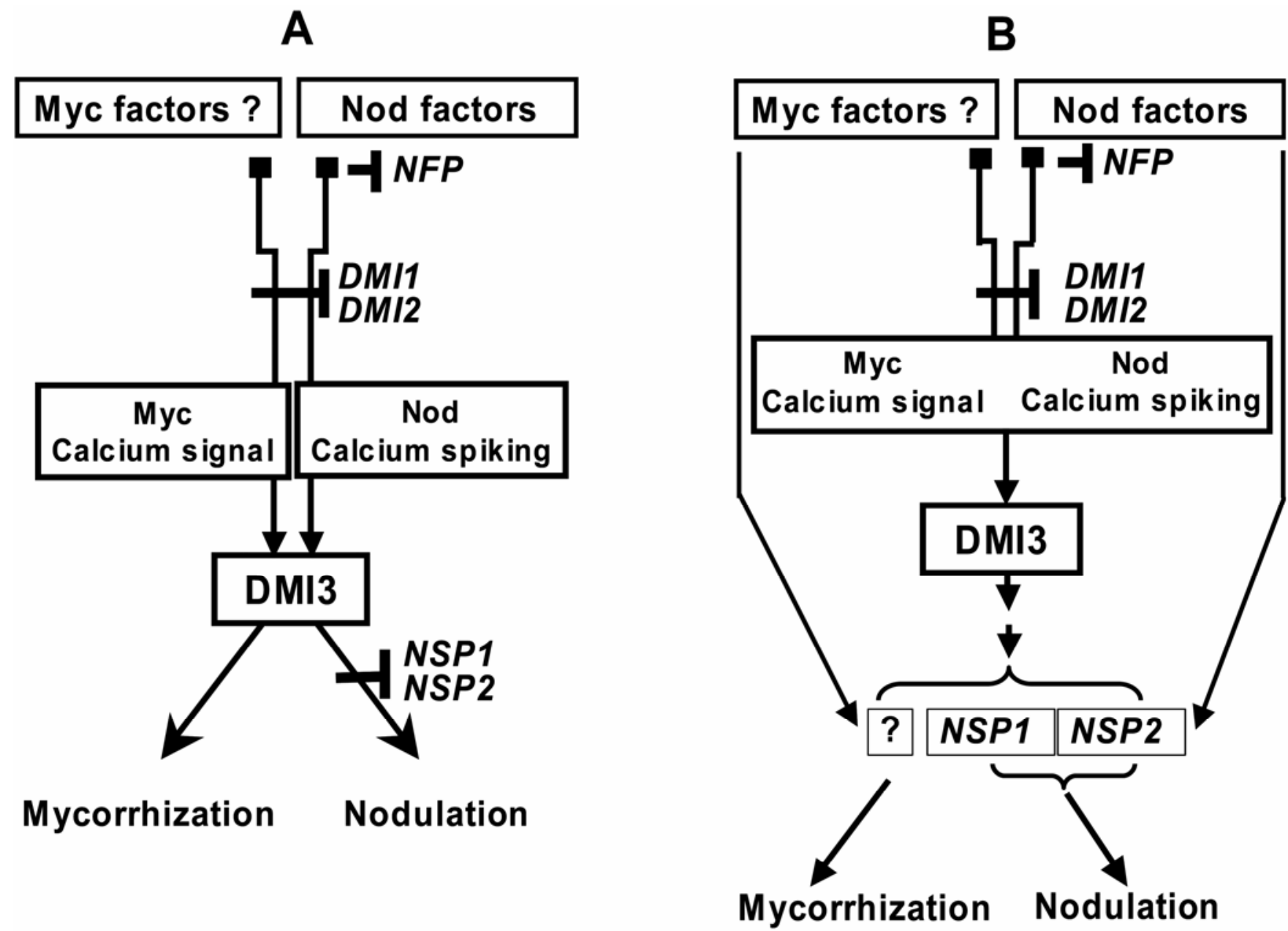

Fig. 1. Two models for the switch between the Nod and mycorrhizal (Myc) signaling pathways. A, The switch is controlled by DMI3, which is able to discriminate between the $\mathrm{Ca}^{2+}$ spiking elicited by Nod factors (NFs) and a hypothetical calcium signal elicited by the fungus. B, DMI3 cannot discriminate between the calcium signals, and the switch, which is controlled by additional signaling pathways, occurs downstream of DMI3, possibly involving GRAStype transcription factors such as NSP1 and NSP2. 
ence of the rice CCaMK gene in a dmi3 mutant could allow the induction by $S$. meliloti of the expression of the early nodulin gene MtENODI1.

In a wild-type background, the pMtENOD11-GUS transgene is constitutively expressed in root tips, and strongly induced by $S$. meliloti or purified $S$. meliloti NFs in epidermal and root hair cells in the region of developing root hairs (Journet et al. 2001).

In the presence of $S$. meliloti, only the nonsymbiotic expression in root tips could be observed in the negative control (dmi3-1 lines transformed by the vector alone). In contrast, roots of dmi3-1 mutants transformed with the rice CCaMK showed, in addition to this nonsymbiotic expression, $\beta$-glucuronidase (GUS) activity in epidermal and root hair cells (data not shown). The observed pattern of expression, mainly in root hairs toward the tips of main and lateral roots, was very similar to that observed in wild-type $M$. truncatula. This result indicates that at least the transducing pathway leading to the induction of MtENODI1 was functionally restored. This symbiotic expression appeared to be NF dependent, because it was not observed in the presence of a nodulation-defective $S$. meliloti nodA mutant, unable to produce NFs. We confirmed this result by showing that purified NFs added at $10^{-9} \mathrm{M}$ induced a similar symbiotic expression of the pMtENOD11-GUS (Fig. 3). Quantitative data presented in Table 1 show that roots exhibiting symbiotic expression of pMtENOD11-GUS were more frequent with dmi3-1 mutants complemented with the rice $\mathrm{CCaMK}$ under the control of the $35 \mathrm{~S}$ promoter than under the control of the M. truncatula DMI3 promoter.

\section{The rice CCaMK restores nodule formation.}

To determine whether the rice CCaMK was able to further complement the symbiotic defects of $d m i 3$ mutants, we examined the roots for the presence of nodules. For dmi3 mutants complemented by the rice CCaMK gene under the control of the $35 S$ promoter and, with a much lower frequency, those complemented by the rice CCaMK gene under the control of the DMI3 promoter, nodule-like structures could be observed 3 weeks after inoculation (Fig. 4; Table 2). These nodular structures remained white and spherical whereas, for control plants complemented by the wild-type $M$. truncatula DMI3 gene, nodules could be observed 1 week after inoculation, some of which developed into long pink nodules. Microscopic observations revealed that nodular structures formed on mutants complemented by the rice CCaMK gene showed an anatomy typical of indeterminate nodules, characterized by the presence of peripheral vascular bundles and surrounding endodermis (Fig. 4). Thus, it appears that the CCaMK from rice is able to restore the signal transduction pathway leading to cortical cell divisions and nodule formation.

\section{$D M I 3$ is involved in the control of the infection process.}

Because they were white and spherical, the nodular structures formed on dmi3 mutant roots complemented by the rice $\mathrm{CCaMK}$ gene were not expected to be functional. Nonfunctional nodules often result from a lack of infection; therefore, we inoculated our constructs with $S$. meliloti strains carrying either a constitutively expressed lac $Z$ or a green fluorescent protein $(G F P)$ reporter gene, in order to monitor the infection process.

Microscopic studies showed that when the rice CCaMK was under the control of the MtDMI3 promoter, no root hair curling or infection thread formation could be detected. In contrast, when the CCaMK gene was under the control of the $35 \mathrm{~S}$ promoter, characteristic root hair curling in the form of shepherd's crooks could be observed. Abnormal infection threads with saclike structures were initiated which generally aborted within root hairs (Fig. 5A), resulting in nodules devoid of bacteria. Sometimes, GFP expression was detected inside the nodules, corresponding to the progression of infection threads into nodule tissues (Fig. 5B). However, out of 15 nodules showing this GFP expression, none showed plant cells in which bacteria had been liberated (Fig. 5C). In contrast, when complementation was performed with the DMI3 wild-type gene, development of infection threads followed by release of bacteria into nodule cells were observed, as expected (Fig. 5D and E).

\section{DISCUSSION}

DMI3 is a shared component between NF signaling and the mycorrhizal symbiosis; therefore, the role of this CCaMK might be to interpret the $\mathrm{Ca}^{2+}$ spiking elicited by NFs, as well as a pu-

OS SLIPLAPRVFDLFDNNRDGTVDMREILCGFSSLRNSRGDDALRLCFQMYDADRSGCISKEELASMLRALPEECLPGDITEPGKLDEVFDQMDADSDGKVT

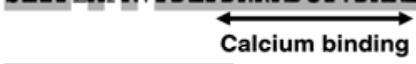

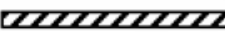
Calcium binding
Calcium

FDEFKAAMQRDSSLQDVVISSIRP.

OS $\underset{. \rightarrow}{\rightarrow}$

\section{Kinase domain}

Fig. 2. Conservation of Medicago truncatula DMI3 (GenBank AY502066) and Oryza sativa CCaMK (GenBank AK070533). Sequence alignment has been done by Multalin (Corpet 1988). 
tative mycorrhizal calcium signature, which remains to be identified. In this article, we addressed the question of whether the ability of legume CCaMKs to recognize and interpret the NFelicited calcium signature results from a functional adaptation during evolution. Surprisingly, we found that a CCaMK from rice, a monocot, phylogenetically distant from legumes, restored nodulin gene induction and nodule formation ability to a dmi3 mutant, which is strictly nodulation deficient. The nodules were less numerous than when the complementation was performed with the MtDMI3 gene, which suggests that the rice CCaMK is less efficient than the DMI3 gene to restore the symbiotic transduction pathway. Furthermore, of the two promoters tested, the restoration was much more efficient when the rice gene was under the control of the strong $35 \mathrm{~S}$ promoter, suggesting that overexpression of the gene can partly compensate for a relative lack of efficiency of the enzyme. This result indicates that a protein of a plant which has not been submitted to any selection pressure for the recognition of NFs is able to both interpret the $\mathrm{Ca}^{2+}$ spiking elicited by NFs and properly transduce the signal via downstream targets to nodule organogenesis. Thus, it seems unlikely that DMI3 plays a role of switch, able to discriminate between calcium signatures of rhizobial or mycorrhizal origin and then trigger the appropriate signaling pathway, according to
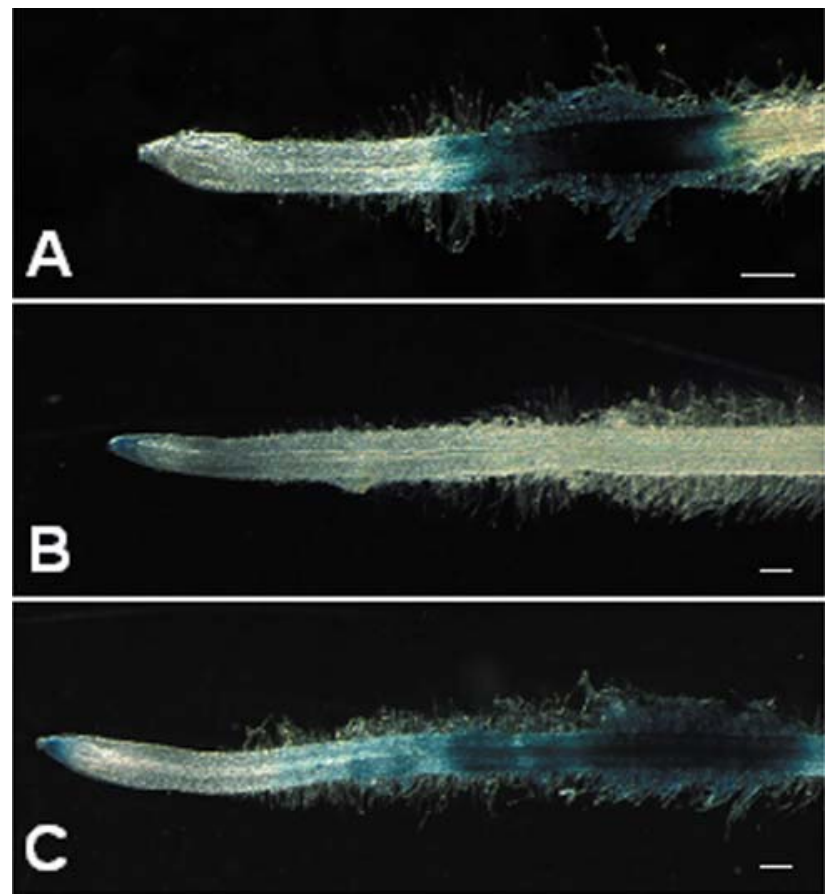

Fig. 3. Histochemical localization of $\beta$-glucuronidase (GUS) activity in roots of transgenic lines expressing $\mathrm{p} M t E N O D 11-G U S$ in response to purified Nod factors. A, Wild type; B, dmi3-1 mutant transformed by the pGreen0049 vector; C, dmi3-1 mutant transformed by the pGreen0049-p35S-rice calcium- and calmodulin-dependent protein kinase. Scale bar $=200 \mu \mathrm{m}$. the nature of the microsymbiont. It seems more likely that both the calcium signatures and the DMI3 downstream targets are roughly similar in rhizobial and mycorrhizal symbioses. In this case, the specific triggering of the appropriate responses in the legume host would be controlled by additional signaling pathways. Because the additional Nod pathway is not expected to be recognized by $\mathrm{CCaMKs}$ from nonlegumes, the integration is likely to occur downstream of DMI3, implying that an unknown protein would play the role of switch between the nodulation and mycorrhization signaling pathways. Another possibility could be that this additional signaling pathway activates NSP2, a predicted transcription factor of the GRAS family, which is localized to the nuclear envelope and the endoplasmic reticulum, and migrates into the nucleus upon Nod factor signaling (Kalo et al. 2005). In the nucleus, the activated NSP2 protein and NSP1, another potential nuclear transcription factor of the GRAS family (Smit et al. 2005), could be activated directly or indirectly by DMI3, and induce the transcription of target genes. In the case of the mycorrhizal signaling pathway, a hypotheticcal different GRAS-type transcription factor could be responsible for activation of the target genes (Fig. 1B).

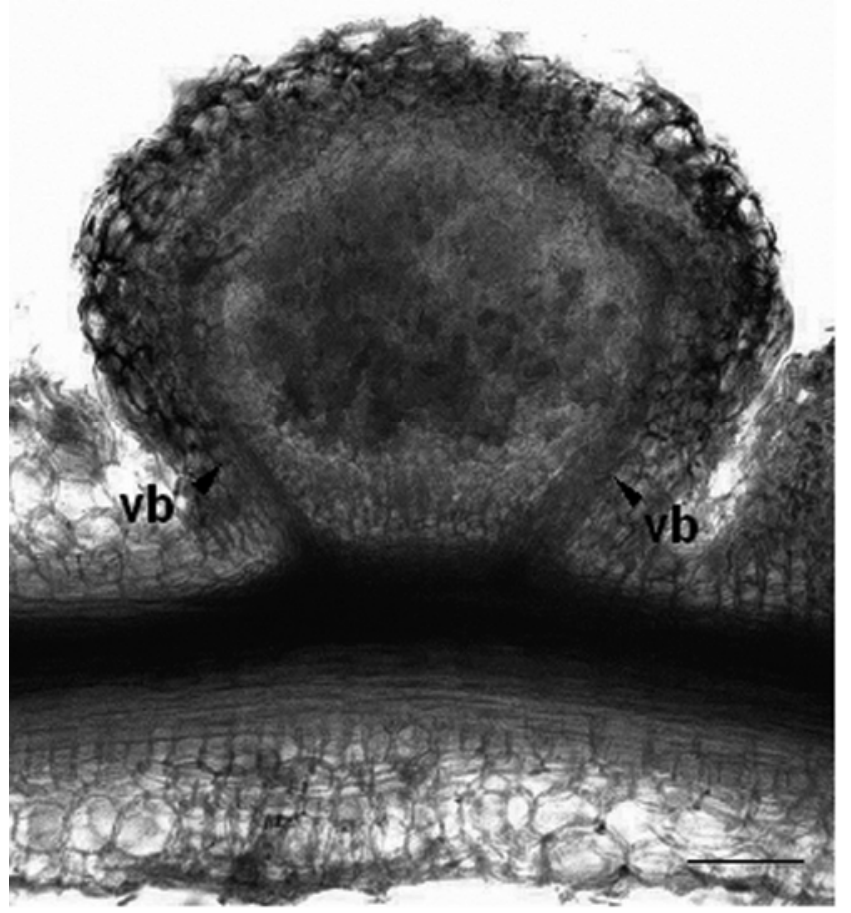

Fig. 4. Bright-field longitudinal section of a 5-week-old nodule-like structure induced by Sinorhizobium meliloti on dmi3-1 mutant roots transformed by pGreen49-p35S-rice calcium- and calmodulin-dependent protein kinase. The presence of peripheral vascular bundles $(\mathrm{vb})$ is characteristic of nodule anatomy in Medicago truncatula. Scale bar $=100 \mu \mathrm{m}$.

Table 1. Occurrence of primary roots showing symbiotic induction of the pMtENOD11-GUS reporter gene by purified Nod factors (NFs) (10 $\left.{ }^{-9} \mathrm{M}\right)$

\begin{tabular}{|c|c|c|c|c|c|}
\hline \multirow[b]{3}{*}{ Plant background } & \multirow[b]{3}{*}{ Plasmid $^{b}$} & \multicolumn{4}{|c|}{ Treatment $^{\mathrm{a}}$} \\
\hline & & \multicolumn{2}{|c|}{$-\mathrm{NFs}$} & \multicolumn{2}{|c|}{$+\mathrm{NFs}$} \\
\hline & & No. of plants & No. symbiotic & No. of plants & No. symbiotic \\
\hline WT pMtENOD11-GUS & pGreen0049 vector & NT & NT & 49 & 38 \\
\hline dmi3-1 pMtENOD11-GUS & pGreen0049 vector & 17 & 0 & 67 & 0 \\
\hline dmi3-1 $\mathrm{pMtENOD11-GUS}$ & pGreen0049-pDMI3-RiceCCaMK & 29 & 0 & 114 & 3 \\
\hline dmi3-1 pMtENOD11-GUS & pGreen0049-p35S-RiceCCaMK & 41 & 0 & 114 & 16 \\
\hline
\end{tabular}

\footnotetext{
${ }^{a}$ Results are the compilation of three independent experiments. No. symbiotic $=$ number of plants showing symbiotic expression; NT $=$ not tested.

${ }^{\mathrm{b}}$ Transforming binary plasmid.
} 
The finding that a CCaMK from a monocot is able to transduce the NF signal raises the question of the ability of nonlegumes to perceive and respond to NFs. As reported by Reddy and associates (1998), in transgenic rice plants, NFs can induce the expression of a GUS reporter gene under the control of the promoter of the early nodulin gene MtENOD12. This suggests that genes controlling NF perception and transduction leading to the induction of MtENOD12 are present in this species. This result is consistent with the results reported by Prithiviraj and associates (2003), which show that germination and early growth of rice and of other nonlegume species are stimulated by the addition of NFs. Altogether, these results indicate that genes controlling the early steps of the NF signal- ing pathway are present and functional in plant species able to establish a symbiotic interaction with AM fungi.

All dmi3 mutants studied so far are loss-of-function mutants, which are blocked at a very early step of nodule formation. Therefore, they are not informative concerning the possible involvement of the DMI3 gene in later symbiotic stages. Here, we showed that dmi3 mutant plants complemented by the rice $\mathrm{CCaMK}$ gene show alterations in the infection process. Interestingly, it has been shown, using S. meliloti mutants, that nodule organogenesis and infection can be uncoupled, suggesting that the two processes implicate different recaptors (Ardourel et al. 1994). Our observations suggest that DMI3 not only is involved in nodule organogenesis but also

Table 2. Occurrence of nodules 21 days after inoculation by Sinorhizobium meliloti ${ }^{\mathrm{a}}$

\begin{tabular}{llrr}
\hline Plant background & Transforming binary plasmid & No. of plants & No. of nodules \\
\hline WT pMtENOD11-GUS & pGreen0049 vector & 58 & 561 \\
dmi3-1 pMtENOD11-GUS & pGreen0049 vector & 15 & 0 \\
dmi3-1 pMtENOD11-GUS & pGreen0049-pDMI3-RiceCCaMK & 119 & 6 \\
dmi3-1 pMtENOD11-GUS & pGreen0049-p35S-RiceCCaMK & 95 & 108 \\
dmi3-1 pMtENOD11-GUS & pCAMBIA2201-pDMI3-DMI3 & 131 \\
\hline
\end{tabular}

${ }^{\mathrm{a}}$ Results are the compilation of three independent experiments; WT = wild type.
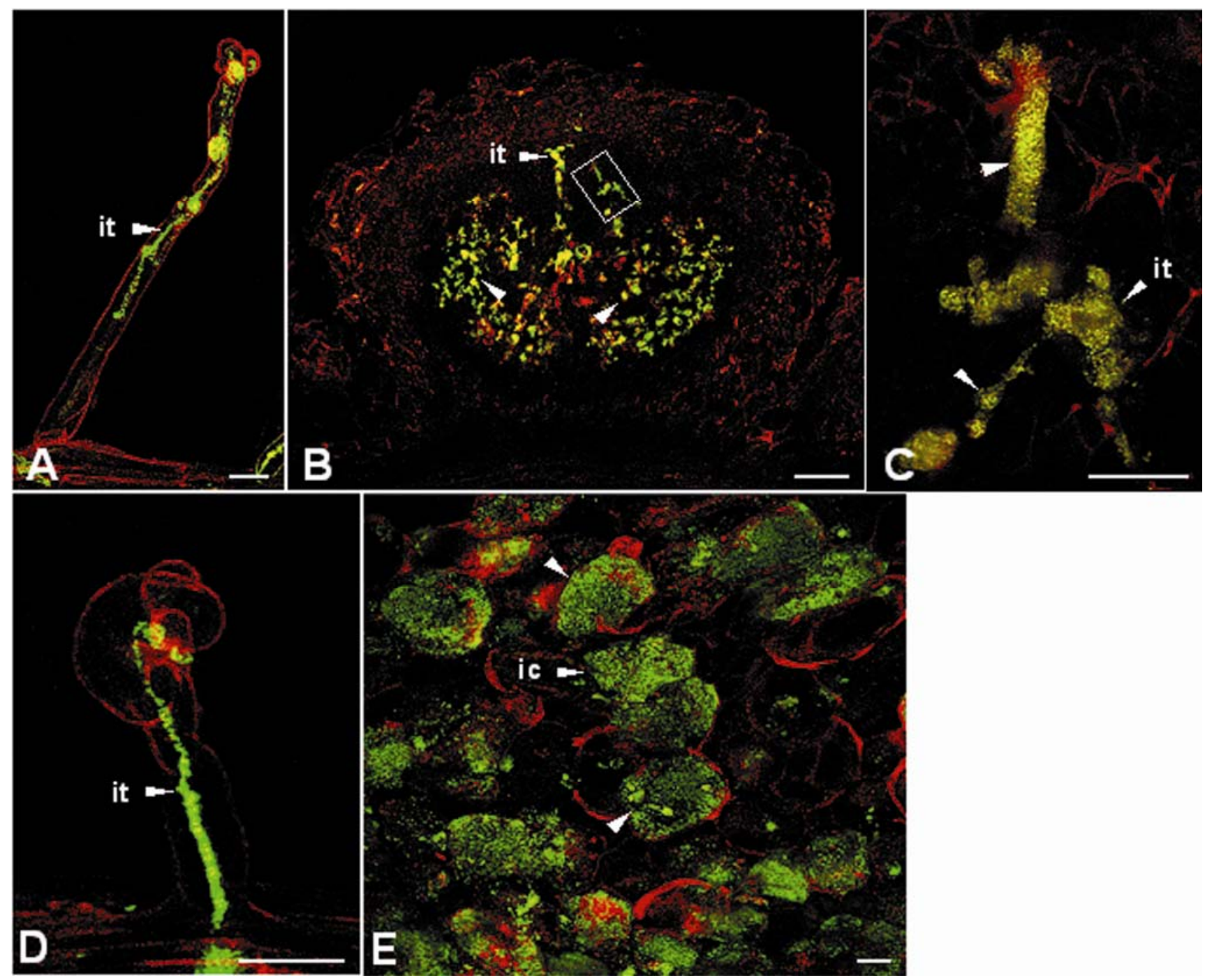

Fig. 5. Infection process observed by confocal microscopy. Bacteria appear in green (GFP) and autofluorescence in red. A through C, The dmi3-1 mutant roots transformed by pGreen0049-p35S-rice calcium- and calmodulin-dependent protein kinase. Infection threads either A, aborted within roots hairs or B, continued into nodule tissues, with an enlarged diameter, without releasing bacteria into plant cells; C, enlarged view of framed region of B. D and E, The dmi3-1 mutant roots transformed by MtDMI3 (positive control). The bacteria $\mathbf{D}$, formed normal infection threads from which they $\mathbf{E}$, invaded nodule cells. Scale bar is $20 \mu \mathrm{m}$ for A, C, D, and E and $80 \mu \mathrm{m}$ for B; it = infection threads; ic = invaded cells. 
in the signaling pathway controlling the infection process, which is consistent with its expression in the infection zone of nitrogen-fixing nodules reported by Limpens and associates (2005). It is noteworthy that the rhizobial infection process, which appears to be more stringent for NF structure than nodule organogenesis, is likely to involve LysM domaincontaining receptor kinases different from those controlling nodule formation (Limpens et al. 2003). Despite this, the nodule organogenesis and the rhizobial infection process apparently involve common transduction cascade elements because at least DMI2 (Capoen et al. 2005; Limpens et al. 2005) and DMI3 (present work) appear to play roles in both these symbiotic processes. Because of the nature of DMI3, it is likely that the rhizobial infection signaling pathway, like those controlling nodule and mycorrhizae formation, involves the generation of a calcium signal.

Altogether, our results suggest that legumes have recruited pre-existing CCaMKs, which did not need major evolutionary adaptation to allow the functioning of the signaling pathway leading to nodule organogenesis. In contrast, the signaling pathway controlling the infection process, which has been reported to present more stringent requirements for the structure of the NFs, also seems to have more strict requirements concerning the properties of CCaMKs. Thus, the specialization of CCaMKs in legumes could have been driven by infectionrelated constraints.

\section{MATERIALS AND METHODS}

\section{Plant growth and transformation conditions.}

M. truncatula plants (wild-type A17 and its derivatives) were grown according to Catoira and associates (2000). A. rhizogenes-mediated transformation of plant roots was conducted according to Boisson-Dernier and associates (2001). Transformed roots were positively selected on Fahraeus agar medium (Catoira et al. 2000) supplemented with kanamycin at $20 \mathrm{mg} /$ liter for 2 weeks at $20^{\circ} \mathrm{C}$.

Composite plants then were transferred into growth pouches with $7 \mathrm{ml}$ of Fahraeus liquid medium devoid of kanamycin (three to four plants/pouch) and further incubated at $25^{\circ} \mathrm{C}$ for 1 week before addition of purified NFs or S. meliloti. In the absence of kanamycin, nontransformed roots also developed.

\section{Plasmid construction.}

A full-length CCaMK cDNA clone identified from the Rice Genome Project developed by the National Institute of Agrobiological Sciences (Japan) and provided by the Rice Genome Resource Center (accession number J023060B22) was used as a DNA source to insert the rice CCaMK gene under the control of either the $35 S$ promoter or the MtDMI3 native promoter.

An HindIII/BamHI fragment from the pBi121 vector containing the $35 S$ promoter was inserted into the pGreen0049 binary vector (Hellens et al. 2000) digested with the same enzymes. Next, a $\mathrm{Bcl}$ I/SpeI fragment containing the rice CCaMK gene was cloned into this pGreen0049-p35S construction between the BamHI and SpeI restriction sites.

An $X b a \mathrm{I} / N c o$ I fragment containing the MtDMI3 native promoter region and part of the coding region was introduced into the pGreen0049. An NcoI digestion followed by a self-ligation allowed the elimination of a 1,843-bp fragment of the DMI3 coding region. An $M f e \mathrm{I} / K p n \mathrm{I}$ fragment containing the rice CCaMK gene then was cloned into this pGreen0049-pDMI3 construction between the EcoRI and KpnI restriction sites.

These two constructions were introduced next into the $A$. rhizogenes strain ARqual (Quandt et al. 1993). The cloning of the M. truncatula DMI3 gene in the binary vector pCAMBIA2201 has been described by Lévy and associates (2004).

\section{Nod factor treatment.}

Plant roots were treated overnight with purified $S$. meliloti Nod factors as described by Catoira and associates (2000).

\section{Nodulation test.}

S. meliloti strain RCR 2011 carrying either the lacZ (plasmid pXLGD4) (Catoira et al. 2000) or the $g f p$ (plasmid pHC60) (Cheng and Walker 1998) reporter genes were added to the plant pouches at a final concentration of approximately $10^{7}$ bacteria/ml. Nodules were scored after 4 weeks at $25^{\circ} \mathrm{C}$.

\section{Microscopic studies.}

Transgenic MtENOD11-GUS plants were stained and observed for $\beta$-glucuronidase activity as described by Catoira and associates (2000). Infection events were observed either by histochemical staining for $\beta$-galactosidase activity, as described by Catoira and associates (2000), or by confocal studies for $g f p$ using a Leica TCS SP2 confocal microscope with $488 \mathrm{~nm}$ excitation for GFP and $543 \mathrm{~nm}$ for autofluorescence. Images were false-colored in green for GFP and red for autofluorescence and combined. Infected root hairs were studied on intact roots and, for observation inside nodules, vibratome sections of $80 \mu \mathrm{m}$ were used.

\section{ACKNOWLEDGMENTS}

We are grateful to $\mathrm{C}$. Gough and J. Dénarié for critical reading of the manuscript and F. de Billy for her expert advice for microscopic observations. O. Godfroy received a Ph.D. grant from the French Ministère de l'Education Nationale, de l'Enseignement Supérieur et de la Recherche.

\section{LITERATURE CITED}

Ardourel, M., Demont, N., Debellé, F., Maillet, F., de Billy, F., Promé, J. C., Dénarié, J., and Truchet, G. 1994. Rhizobium meliloti lipooligosaccharide nodulation factors: different structural requirements for bacterial entry into target root hair cells and induction of plant symbiotic developmental responses. Plant Cell 6:1357-1374.

Boisson-Dernier, A., Chabaud, M., Garcia, F., Bécard, G., Rosenberg, C., and Barker, D. G. 2001. Agrobacterium rhizogenes-transformed roots of Medicago truncatula for the study of nitrogen-fixing and endomycorrhizal symbiotic associations. Mol. Plant Microbe Interact. 14:695700.

Capoen, W., Goormachtig, S., De Rycke, R., Schroeyers, K., and Holsters, M. 2005. SrSymRK, a plant receptor essential for symbiosome formation. Proc. Natl. Acad. Sci. U.S.A. 102:10369-10374.

Catoira, R., Galera, C., de Billy, F., Penmetsa, R. V., Journet, E. P., Maillet, F., Rosenberg, C., Cook, D., Gough, C., and Dénarié, J. 2000. Four genes of Medicago truncatula controlling components of a Nod factor transduction pathway. Plant Cell 12:1647-1666.

Cheng, H. P., and Walker, G. C. 1998. Succinoglycan is required for formation and elongation of infection threads during nodulation of alfalfa by Rhizobium meliloti. J. Bacteriol. 180:5183-5191

Corpet, F., 1988. Multiple sequence alignment with hierarchical clustering. Nucleic Acids Res. 16:10881-10890.

Dénarié, J., Debellé, F., and Promé, J. C. 1996. Rhizobium lipo-chitooligosaccharide nodulation factors: signaling molecules mediating recognition and morphogenesis. Annu. Rev. Biochem. 65:503-535.

Geurts, R., and Bisseling, T. 2002. Rhizobium Nod factor perception and signaling. Plant Cell (Suppl.) 14:S239-249.

Gianinazzi-Pearson, V. 1996. Plant cell responses to arbuscular mycorrhizal fungi: getting to the roots of the symbiosis. Plant Cell 8:1871-1883.

Harrison, M. J. 2005. Signaling in the arbuscular mycorrhizal symbiosis. Annu. Rev. Microbiol. 59:19-42.

Hellens, R. P., Edwards, E. A., Leyland, N. R., Bean, S., and Mullineaux, P. M. 2000. pGreen: a versatile and flexible binary Ti vector for Agrobacterium-mediated plant transformation. Plant Mol. Biol. 42:819-832.

International Rice Genome Sequencing Project, 2005. The map-based sequence of the rice genome. Nature 436:793-800.

Journet, E. P., El-Gachtouli, N., Vernoud, V., de Billy, F., Pichon, M., Dedieu, A., Arnould, C., Morandi, D., Barker, D. G., and GianinazziPearson, V. 2001. Medicago truncatula ENOD11: a novel RPRP-encoding early nodulin gene expressed during mycorrhization in arbusculecontaining cells. Mol. Plant-Microbe Interact. 14:737-748. 
Kalo, P., Gleason, C., Edwards, A., Marsh, J., Mitra, R. M., Hirsch, S. Jakab, J., Sims, S., Long, S. R., Rogers, J., Kiss, G. B., Downie, J. A., and Oldroyd, G. E. 2005. Nodulation signaling in legumes requires NSP2, a member of the GRAS family of transcriptional regulators. Science 308:1786-1789.

Lévy, J., Bres, C., Geurts, R., Chalhoub, B., Kulikova, O., Duc, G., Journet, E. P., Ané, J. M., Lauber, E., Bisseling, T., Dénarié, J., Rosenberg, C., and Debellé, F. 2004. A putative $\mathrm{Ca} 2+$ and calmodulin-dependent protein kinase required for bacterial and fungal symbioses. Science 303:1361-1364.

Limpens, E., Franken, C., Smit, P., Willemse, J., Bisseling, T., and Geurts, R. 2003. LysM domain receptor kinases regulating rhizobial Nod factor-induced infection. Science 302:630-633.

Limpens, E., Mirabella, R., Fedorova, E., Franken, C., Franssen, H., Bisseling, T., and Geurts, R. 2005. Formation of organelle-like N2-fixing symbiosomes in legume root nodules is controlled by DMI2. Proc. Natl. Acad. Sci. U.S.A. 102:10375-10380.

Madsen, E. B., Madsen, L. H., Radutoiu, S., Olbryt, M., Rakwalska, M., Szczyglowski, K., Sato, S., Kaneko, T., Tabata, S., Sandal, N., and Stougaard, J. 2003. A receptor kinase gene of the LysM type is involved in legume perception of rhizobial signals. Nature 425: 637-640.

Mitra, R. M., Gleason, C. A., Edwards, A., Hadfield, J., Downie, J. A., Oldroyd, G. E., and Long, S. R. 2004. A Ca2+/calmodulin-dependent protein kinase required for symbiotic nodule development: gene identification by transcript-based cloning. Proc. Natl. Acad. Sci. U.S.A. 101:4701-4705.

Oldroyd, G. E., and Downie, J. A. 2004. Calcium, kinases and nodulation signaling in legumes. Nat. Rev. Mol. Cell Biol. 5:566-576.

Oldroyd, G. E., Harrison, M. J., and Udvardi, M. 2005. Peace talks and trade deals. Keys to long-term harmony in legume-microbe symbioses. Plant Physiol. 137:1205-1210.

Patil, S., Takezawa, D., and Poovaiah, B. W. 1995. Chimeric plant calcium/ calmodulin-dependent protein kinase gene with a neural visinin-like calcium-binding domain. Proc. Natl. Acad. Sci. U.S.A. 92:4897-4901.

Prithiviraj, B., Zhou, X., Souleimanov, A., Khan, W. M., and Smith, D. L. 2003. A host-specific bacteria-to-plant signal molecule (Nod factor) enhances germination and early growth of diverse crop plants. Planta 216:437-445.

Quandt, H.-J., Pühler, A., and Broer, I. 1993. Transgenic root nodules of Vicia hirsuta: a fast and efficient system for the study of gene expression in indeterminate-type nodules. Mol. Plant-Microbe Interact. 6:699-706.

Radutoiu, S., Madsen, L. H., Madsen, E. B., Felle, H. H., Umehara, Y., Gronlund, M., Sato, S., Nakamura, Y., Tabata, S., Sandal, N., and Stougaard, J. 2003. Plant recognition of symbiotic bacteria requires two LysM receptor-like kinases. Nature 425:585-592.

Reddy, P. M., Ladha, J. K., Ramos, M. C., Maillet, F., Hernandez, R. J Torrizo, L. B., Oliva, N. P., Datta, S. K., and Datta, K. 1998. Rhizobial lipochitooligosaccharide nodulation factors activate expression of the early nodulin gene ENOD12 in rice. Plant. J. 14:693-702.

Smit, P., Raedts, J., Portyanko, V., Debellé, F., Gough, C., Bisseling, T., and Geurts, R. 2005. NSP1 of the GRAS protein family is essential for rhizobial Nod factor-induced transcription. Science 308:1789-1791.

Wais, R. J., Galera, C., Oldroyd, G., Catoira, R., Penmetsa, R. V., Cook, D., Gough, C., Dénarié, J., and Long, S. R. 2000. Genetic analysis of calcium spiking responses in nodulation mutants of Medicago truncatula. Proc. Natl. Acad. Sci. U.S.A. 97:13407-13412.

Weidmann, S., Sanchez, L., Descombin, J., Chatagnier, O., Gianinazzi, S., and Gianinazzi-Pearson, V. 2004. Fungal elicitation of signal transduction-related plant genes precedes mycorrhiza establishment and requires the DMI3 gene in Medicago truncatula. Mol. Plant-Microbe Interact. 17:1385-1393.

\section{AUTHOR-RECOMMENDED INTERNET RESOURCE}

Rice Genome Resource Center: www.rgrc.dna.affrc.go.jp/ 